Original Research Paper

\title{
Experimental Study on the Microbial Community Structure of the Sediment of Pi River under the Different pH in Winter
}

\author{
Cairui Yu, Dongmei Shen*, Wanfeng Wang, Xinwei Song, Yulan Gao, Youxiao Tu and Xing Jin \\ Department of Architecture and Civil Engineering, West Anhui University, Lu'an237012, China
}

\author{
Article history \\ Received: 05-01-2021 \\ Revised: 11-03-2021 \\ Accepted: 13-03-2021 \\ Corresponding Author: \\ Dongmei Shen \\ Department of Architecture and \\ Civil Engineering, West Anhui \\ University, Lu'an237012, \\ China \\ Email:shdm9832@163.com
}

\begin{abstract}
In order to solve the poor self-purification ability of low temperature water in winter, the microbial community structure in the sediment of Pi River water (located in West Anhui) was investigated experimentally in this study. Firstly, the sediment was sampled in the lower reaches of Pi River and prepared with the different $\mathrm{pH}$ (5.0, 5.5, 7.0 and 8.5); secondly, the prepared samples were tested by the high-throughput sequencing technology and the tested results showed that more than $40 \%$ of the bacteria in the sediment samples had an average relative abundance of less than $1.5 \%$ and the bacterial community was relatively dispersed and diversified; the relative abundance of Acidobacteria was the lowest, while Proteobacteria and Bacteroidetes were the opposite; additionally, the abundances of Nitrosomonadaceae, Nitrospirae and Nitrosomonadales samples $(\mathrm{pH}=5.5,7.0$ and 8.5$)$ were all less than $5 \%$, while the abundance in $\mathrm{pH}=5.0$ samples was less than $1 \%$; the specific species of alkaline sample is 0 , because acidity had a great influence on the structure of microbial community, especially nitrifying bacteria, furthermore, the optimal environment for bacterial growth in sediments had an acidity threshold. Accordingly, this paper will provide a reference for the poor selfpurification of water at low temperature in winter.
\end{abstract}

Keywords: Acidity-Basicity, Riverbed Sediment, Microbial Community Structure, Winter

\section{Introduction}

In recent years, the level of urbanization in China has been continuously improved and the pollution of life, agriculture and industry to urban rivers has been increasing, the results of which the pollution of urban water environment is becoming more and more seriously. Among these pollution problems, the pollution of sewage channels and sediments is particularly problematic, which has become the focus of many studies (Ćosić-Flajsig et al., 2020). The complex pollutants such as solid waste, domestic sewage, initial rainwater and other pollutants are deposited at the bottom of the urban river, which formed the sediment slowly (Bai et al., 2014; Kirchman, 1994; Ruiz-González et al., 2015). Microorganisms in sediment play an important role in the circulation of river ecosystem (Billard et al., 2015; Kaestli et al., 2017), as well as a certain role in regulating river ecosystem, meanwhile, their diversity and community structure are also affected by the varies of environmental factors, such as physical chemistry and biological parameters of environmental conditions (Lapanje et al., 2005; Lundgaard et al., 2017; Tiquia, 2010).

Some researchers implemented that microbial community structure or specific microbial functional groups was used as an important tool to evaluate the heterogeneity or ecological stress of river sediment (Jalili et al., 2018; Kaestli et al., 2017; Xie et al., 2016), the results indicated that the temporal and spatial varies of physical and chemical properties of sediment would inevitably lead to corresponding changes in microbial community structure and the number of specific microbial functional groups (Kaestli et al., 2017; Torres-Alvarado et al., 2016; Chen et al., 2015). Zhang et al. (2019) investigated the sediment in different zones of Nanfeihe River (urban zones, urban-rural zones and rural zones) with seasonal variation and human disturbance and concluded that the chemical parameters had significant regional heterogeneity and no seasonal difference, where the seasonal influence on the structure was greater than that in the region of the whole microbial community and 
the relative abundance of Sclerebia and Bacteroides was more sensitive with seasonal variation.

Wang et al. (2019) conducted the Chaobai River microbial community structure with different groundwater depth and relevant environmental factors, where the endocrine disruptors of Chaobai River surface water enter into the underground aquifer with $360 \mathrm{~m}$ away from the river and $80 \mathrm{~m}$ deep. The vertical distribution of Bisphenol A (BPA), 4-Nonylphenol (NP), Estrone (E1) and Estriol (E3) decreased significantly from the surface to the ground water, which had the primary decay rates of $0.0416,0.0343,0.0498$ and $0.0173 \mathrm{~m}^{-1}$, respectively. The depth, water temperature, conductivity and coexisting anions of aquifer were closely related to the distribution of endocrine disruptors in groundwater. Wang et al. (2018) found that the bacterial composition of surface water along the Jialing River was significantly different, while the distribution of Proteus, cyanobacteria, actinomycetes, bacteroides and acidobacteria were also different and the bacterial diversity in the sediment was significantly higher than that in the corresponding water samples. The sewage flowing into the river contained organic and inorganic pollutants, which changed its $\mathrm{pH}$, temperature, dissolved oxygen content and light penetration, those may further reshape the bacterial community structure (García-Armisen et al., 2014; Mark Ibekwe et al., 2012; Lindström et al., 2005). In addition, the spatial distribution of river bacterial community was also related to landscape and hydrology to some extent (Crump et al., 2007; Lindström et al., 2005). At present, most of the studies on surface water and sediment have been focused on antibiotics, which based on the impact of human activities (Zhou et al., 2019), phenolic, nutrients (Howarth et al., 2000) and algal characteristics (Biggs, 2000; Flynn et al., 2013) and other physical and chemical indicators (Jiménez-Rodríguez et al., 2019; Metwally et al., 2020; Scharnberg et al., 2020). However, compared with marine or lake ecosystems, the diversity of microbial communities is still lack of in-depth study in urban rivers. To the best our knowledge, there are relatively few comprehensive and large-scale literatures on the microbial community structure of sewage river sediments and the research is not concentrated and specific. Existed domestic studies mostly focus on the research on the interference effects of individual points or a certain substance on the microorganisms in the water body and the research on a certain sewage river have not been reported in a specific season. Therefore, this study selected sediments as the main research object, which is the only polluted river (Pi River) in Lu'an City. Meanwhile, the microbial activity in the sediment is reduced because of low river water temperature in winter, however, the pollutants entering the urban river are not reduced, which cause serious water pollution. In order to improve the current situation of river selfpurification, the varies of microbial community structure is analyzed by varying the sediment acidity-basicity $(\mathrm{pH})$ in the river sediment. Moreover, this paper was divided into 4 sections, section 1 begins with the background and proposal of this research; section 2 is concerned with the experimental sample used for this study, in addition, research methods and process are introduced; section 3 presents the findings of this experiment and discusses the key themes that have been identified in analysis; finally, the conclusion gives a brief summary and several research deficiencies need to be investigated in the future.

\section{Experimental Sample and Methods}

\section{Research Object}

Pi River is the only sewage receiving water body in Lu'an City, which is located at the west of Anhui province, China (Longitude $116.5^{\circ}$ and latitude $31.7^{\circ}$ ). The effluent of the urban sewage treatment plants (Chengbei, Dongcheng, Fenghuang Bridge, etc.) all flow into Pi River. Although the design of the effluent reaches the first class A standard, it is still inferior to class $\mathrm{V}$ water; at the same time, the untreated domestic sewage flows into the Pi River along with black and odorous water such as Jiangjiagou River and Junhe River, which affects the water quality of the Pi River. According to the testing, the water quality of Pi River Xin'an ferry had exceeded the standard for three consecutive months from January to March 2018. Analysis showed that winter is characterized by dry and less rain, which resulted in surface runoff less water; whereas the amount of sewage accepted by the river has not decreased. The bacteria are not active owing to the low water temperature, therefore, the river water is basically have no self-purification capacity. To this end, this study intends to sample from the winter Pi River bottom sludge and research the community structure of sediment microbes in the sample by changing the acidity-basicity.

\section{Sample Collection}

Yueliang Island was taken as objects for research in the experiment. The sampling points were selected at the downstream of Pi River, which is adjacent to Yueliang island community and West Anhui University, where there are nearly 20,000 permanent teachers and students in the college and nearly 5,000 residents in Yueliang island community, as shown in Fig. 1. The rainwater and sewage are often not completely separated on the island and some businesses directly pour the catering oil and water into the rainwater inlet, which all affect the water quality of Pi River. On the opposite side of the island is the urban living area with several sewage discharge points. The water samples entering the water body are complex and typical. In the 
experiment, the sediment at the sampling point and the overlying water at the corresponding point were collected on site in November 2018. Samples with thickness of no less than $20 \mathrm{~cm}$ on the surface of the sediment were collected with plexiglass cylinder sampling column and 4 parallel samples were collected at each point. The upper end of the sampling column was covered with overlying water, the two ends were placed with a rubber plug and placed vertically and then brought back to the laboratory quickly.

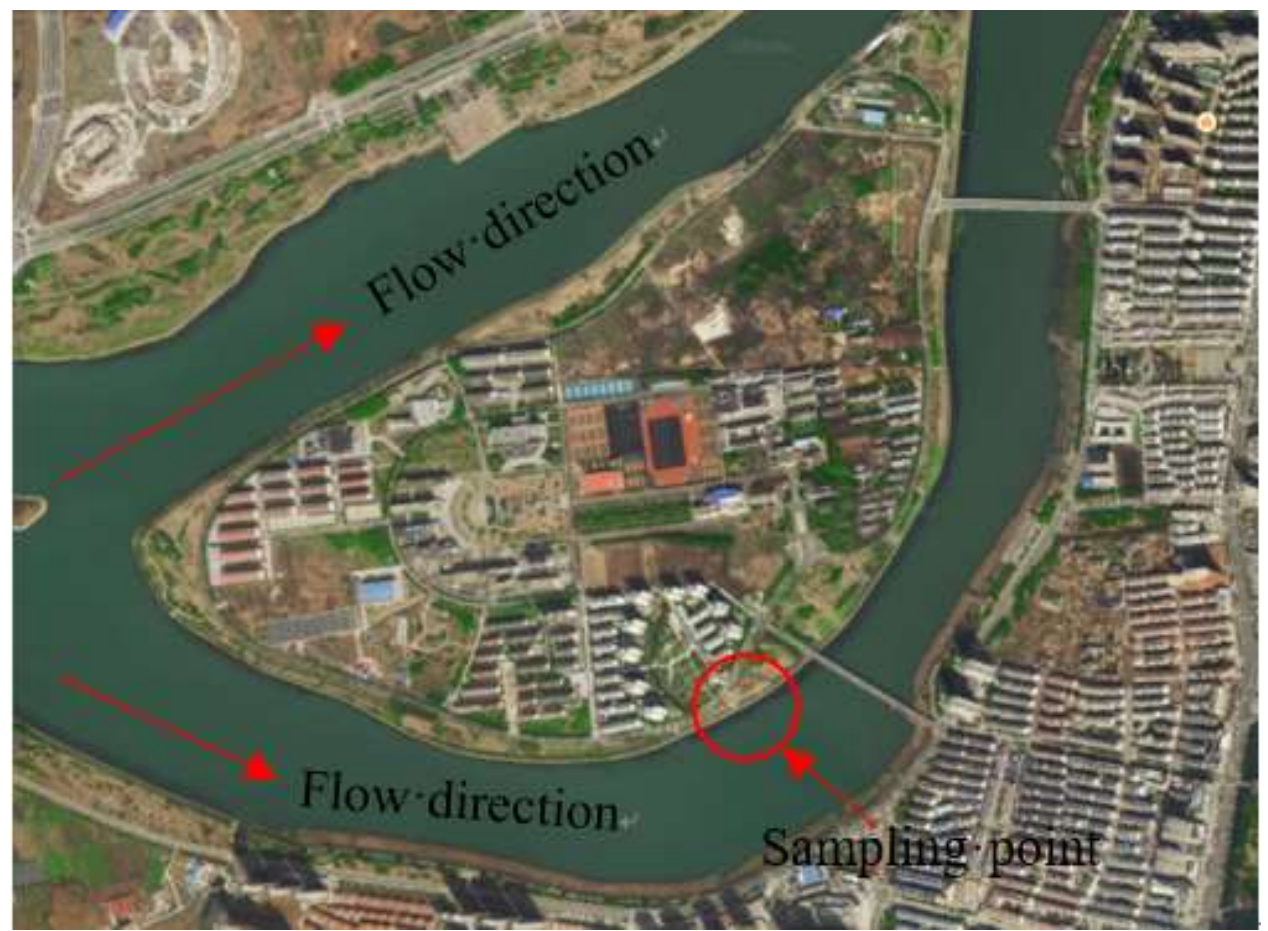

Fig. 1: Schematic diagram of sampling point

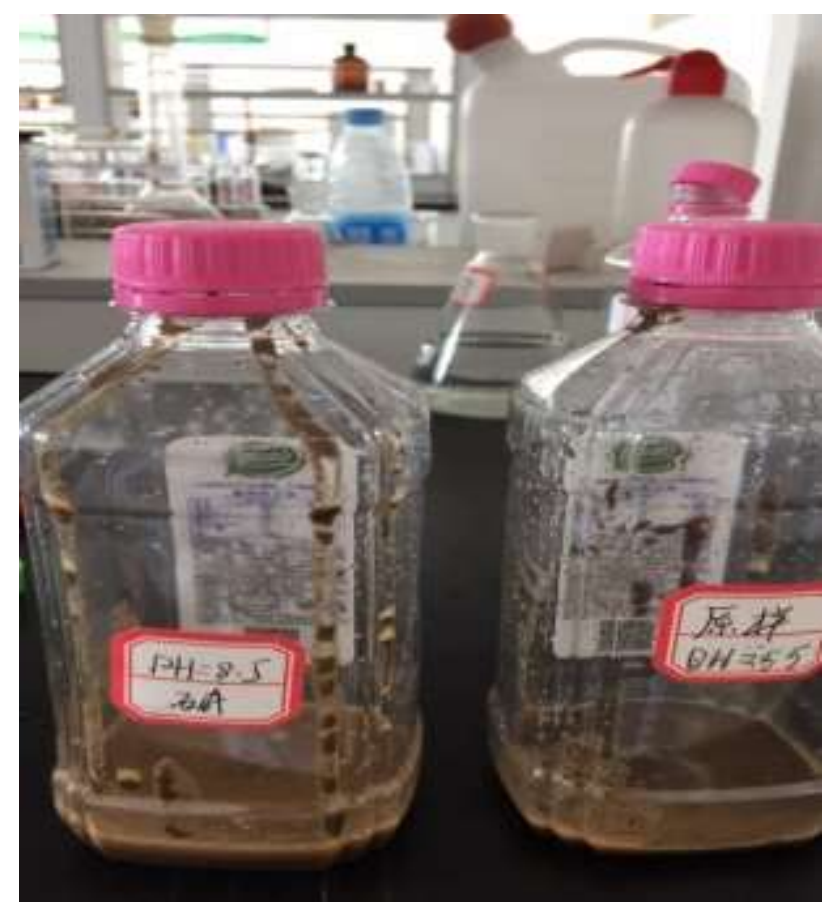

Fig. 2: Different pH samples 


\section{Experimental Methods}

The $10 \mathrm{~cm}$-thick sediment was taken from the surface of each sample column, then remove gravel, weeds and other animal and plant residues. Sediment was placed in the same container and evenly mixed into four parts for adjustment experiments. The above-mentioned uniformly mixed sediment was spread on the bottom of four containers with the thickness of about $10 \mathrm{~cm}$ (named as original sample), the measured $\mathrm{pH}$ is 5.5. The solution of $\mathrm{NaOH}$ and $\mathrm{HCl}$ with low concentration was gradually added to the 3 containers along the wall surface with the siphon and adjusted to $\mathrm{pH}=5.0, \mathrm{pH}=7.0$ and $\mathrm{pH}=8.5$, respectively. Four samples with $\mathrm{pH}=5.5, \mathrm{pH}=5.0, \mathrm{pH}=$ 8.5 and $\mathrm{pH}=7.0$ are successively named $\mathrm{Y} 1, \mathrm{~S} 2, \mathrm{~J} 3$ and Z4, as shown in Fig. 2. At last, the prepared mud samples were sealed with sterile plastic bottles and sent to Beijing Biomaker Co., Ltd. for high-throughput testing.

\section{Measurement and Analysis Methods}

After the sample was transported back to the laboratory, the overlying water at the upper end of the sampling column was siphoned. Meanwhile, the physical and chemical indexes of the water body were measured. In this experiment, the determination of DO, COD and $\mathrm{NH}_{4}-\mathrm{N}$ was applied to the iodine method (GB 7489-87), the dichromate method (GB 11914-89) and the Nessler's Reagent Colorimetry (GB 7479-87) accordingly; the measurement of TN and TP was respectively used for Ultraviolet spectrophotometry with alkaline potassium persulfate digestion (GB 11894-89) and the ammonium molybdate spectrophotometry (GB 11893-89) and the indexes of the water body were shown in the Table 1 .

The original sequencing sequence was filtered and paired-end spliced to obtain the optimized sequence and then OTU was divided. Afterwards, the samples were analyzed on various taxonomic classification levels. After that, the relationship between flora and environmental factors was investigated through Alpha, Beta diversity and RDA/CCA analysis. According to the overlap relationship between PE reads, the paired-end sequence data obtained was spliced into a sequence of tags by Hiseq sequencing and the same time, the quality of the reads and the effect of Merge were quality-controlled and filtered, which includes three processes (1) PE reads stitching, (2) Tags filtering and (3) chimera removal. Finally, some conclusions were achieved based on the experiments after analysis and discussion and the detailed experimental flowchart was shown in Fig. 3.

\section{Experimental Process}

After extracting the total DNA of the sample, the primers were designed according to the conserved region, which added the sequencing connector at the end of primer. The primers were amplified by PCR technology and its products were purified, quantified and homogenized to form a sequencing database. The original image data files were transformed into the Sequenced Reads by Base Calling analysis, which obtained by high-throughput sequencing with Illumina HiSeq and other sequencing platforms.

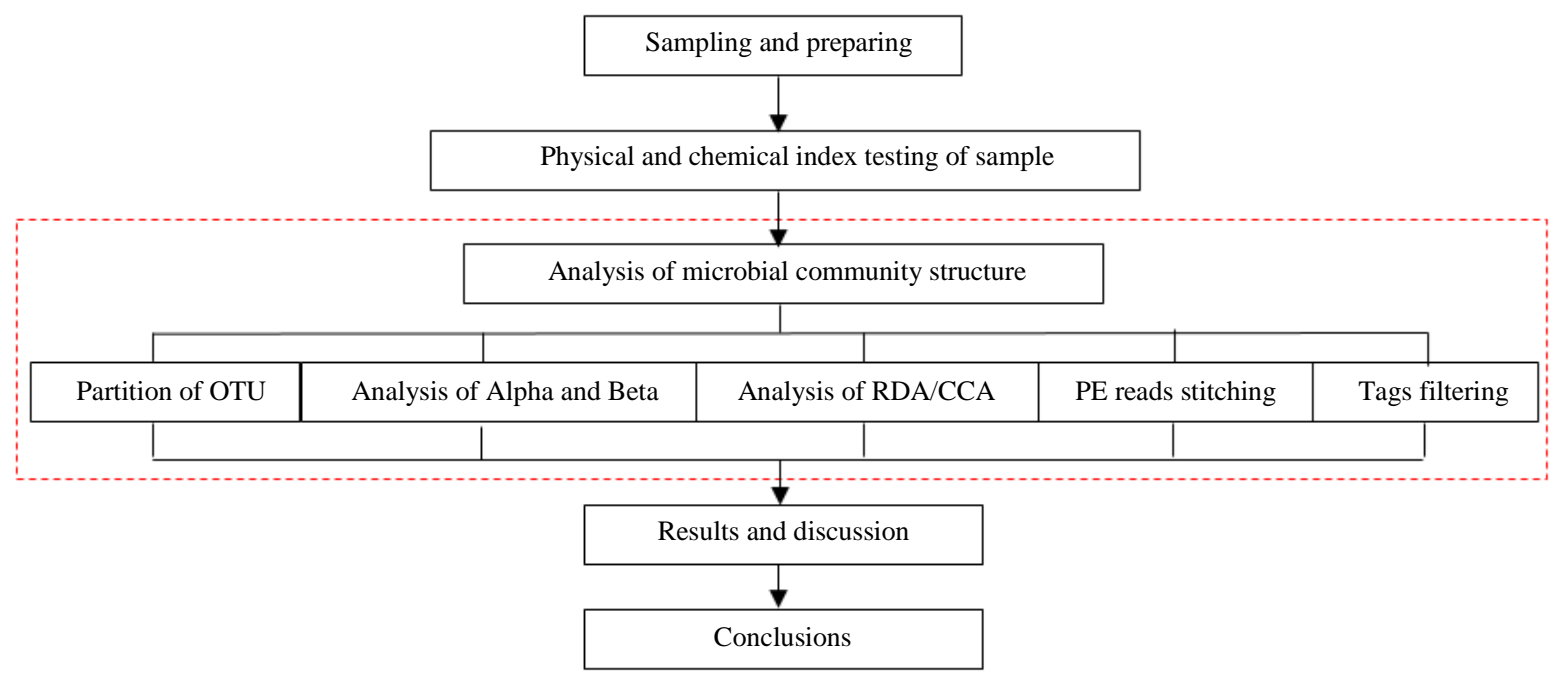

Fig. 3: Flow chart of the experiment

Table 1: Water quality index of overlying water

\begin{tabular}{lllllll}
\hline Index & $\mathrm{T}\left({ }^{\circ} \mathrm{C}\right)$ & $\mathrm{DO}(\mathrm{mg} / \mathrm{L})$ & $\mathrm{COD}(\mathrm{mg} / \mathrm{L})$ & $\mathrm{NH}_{4}-\mathrm{N}(\mathrm{mg} / \mathrm{L})$ & $\mathrm{TN}(\mathrm{mg} / \mathrm{L})$ & $\mathrm{TP}(\mathrm{mg} / \mathrm{L})$ \\
\hline Value & 8 & 8.5 & 37 & 0.35 & 2.7 & 0.16 \\
\hline
\end{tabular}




\section{Results and Analysis}

\section{Diversity of Four Different pH Samples}

Four samples were sequenced to obtain 320, 155 pairs of Reads and 219, 058 clean tags were generated by splicing and filtering of two terminal Reads, which produced at least 53, 305 clean tags and an average of 54, 765 clean tags per sample. It could be seen that the bacteria population was rich in the bottom mud of Pi River.

After enrichment and culture of sediment samples with 4 different $\mathrm{pH}$ and at the $97 \%$ similarity level, the diversity index of Alpha was shown in Table 2. As seen from Table 2, the OTU numbers of the four samples was respectively 1164 (Y1), 923 (S2), 1154 (J3) and 1135 (Z4), among which S2 was the least, far lower than Y1, while J3 was close to Y1; the results show that the acid environment had a significant impact on microorganisms, while the alkaline environment had little impact on the original microorganisms. As the same time, it may be closely related to the physiological activities of microorganisms and the $\mathrm{pH}$ of the environment. Only under the appropriate $\mathrm{pH}$, microorganisms performed normal physiological activities. Microorganisms have an optimum $\mathrm{pH}$ range of between 6.5 and 8.5, which involved in biological treatment of sewage generally. In the too acidic conditions, the TP and TN in the sediment are negatively released. Similarly to the research of literature, the TP and TN of sediment were released negatively under too low $\mathrm{pH}$. The community richness of the enriched samples can be estimated by ACE and Chao1 indexes and its community diversity can be estimated by Shannon and Simpson indexes. As shown in Table 2, it can be seen that the community diversity of the four sediment enriched samples was relatively similar and the richness of $\mathrm{J} 3$ sample is the highest, indicating that alkaline environment is conducive to the growth of microorganisms, which is similar to the TP and Simpson indexes in the sediment under alkaline conditions. As listed in Fig. 4, the community diversity of 4 sediment enrichment samples was similar, among which J3 sample had the highest abundance, which indicated that alkaline environment was conducive to the growth of microorganisms; the TP and TN were released positively under alkaline condition.

The Rank Abundance Curve was shown in Fig. 4, the species richness and evenness of Y1, J3 and Z4 samples were higher than those of S2 samples. It may be closely related to the physiological activities of microorganisms and the $\mathrm{pH}$ of the environment. The microorganisms conduct normal physiological activities under the appropriate $\mathrm{pH}$.

Table 2: Diversity index statistics of the Alpha

\begin{tabular}{lrlllll}
\hline Sample ID & OTU & ACE & Chao1 & Simpson & Shanon & Coverage \\
\hline J3 & 1154 & 1165.5328 & 1170.8929 & 0.0168 & 5.7100 & 0.9988 \\
S2 & 923 & 1009.7692 & 1011.1250 & 0.0182 & 4.9323 & 0.9963 \\
Y1 & 1164 & 1178.4386 & 1184.7188 & 0.0216 & 5.5994 & 0.9984 \\
Z4 & 1135 & 1153.6464 & 1166.0000 & 0.0209 & 5.5502 & 0.9983 \\
\hline
\end{tabular}

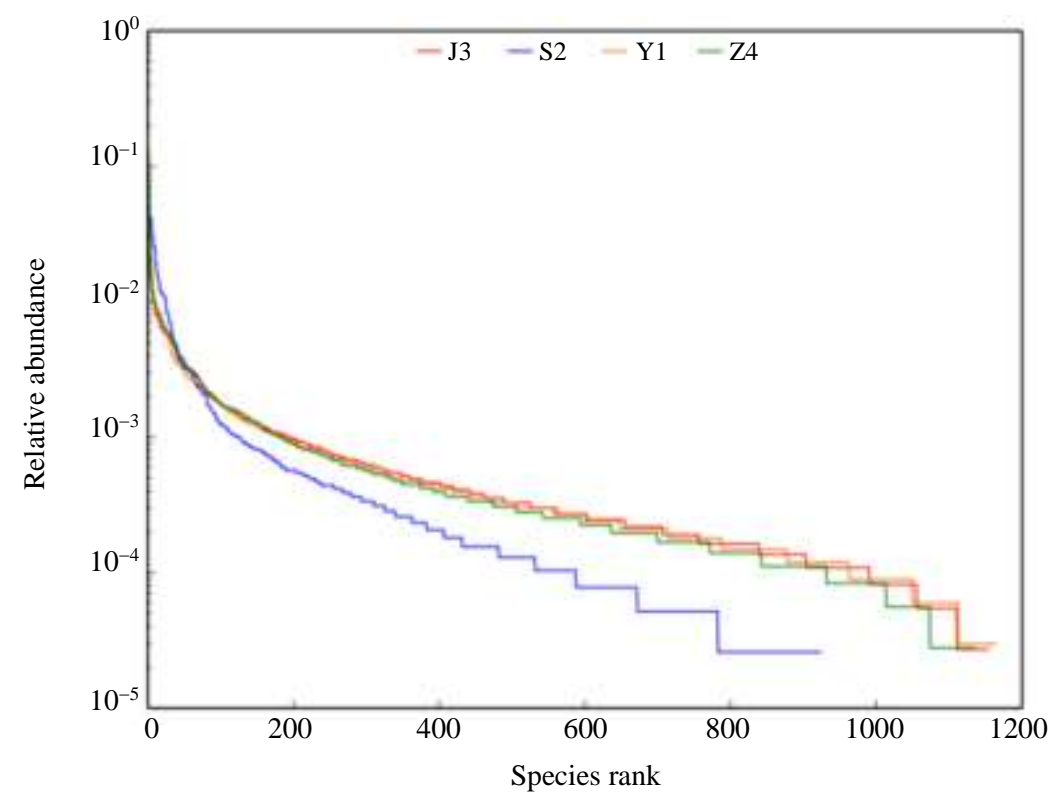

Fig. 4: The curve of Sample rank abundance 


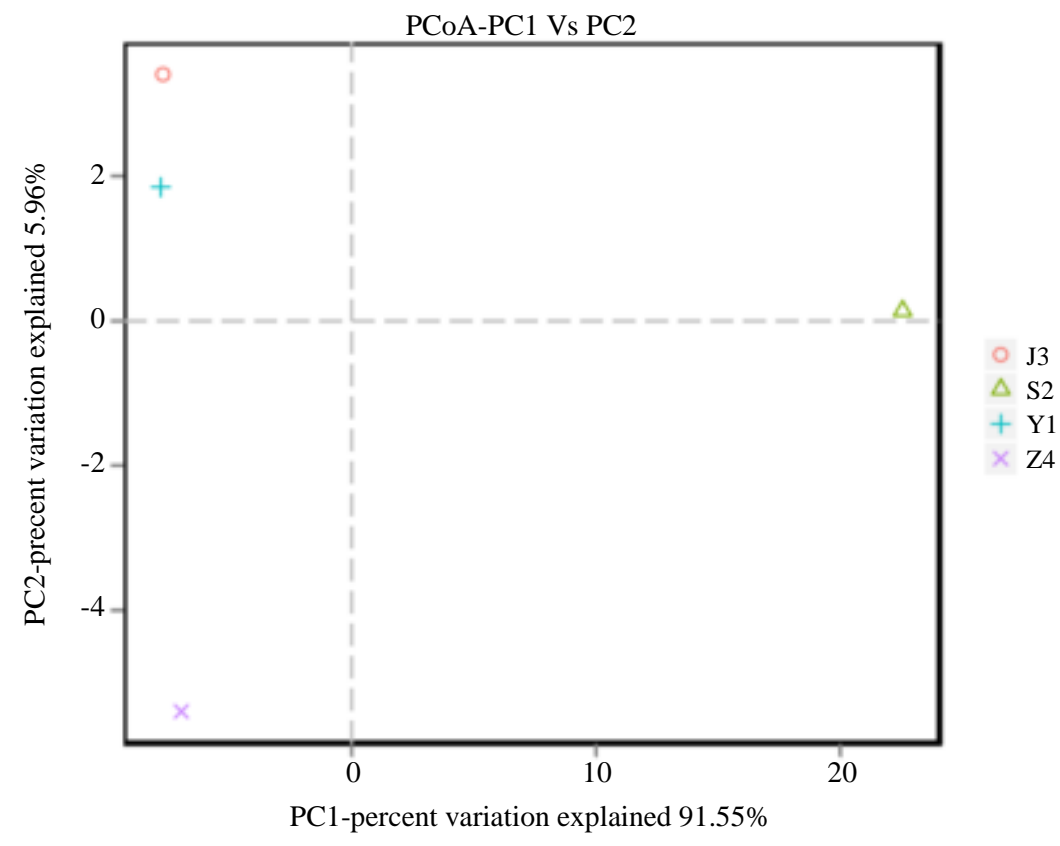

Fig. 5: Analysis of the sample difference (PCoA)

\section{Diversity Analysis of Sample Beta}

As evident in Fig.5, the contribution of PC1 axis and PC2 axis was 91.55 and $5.96 \%$, respectively, while the cumulative contribution rates of the two axes were $97.51 \%$. Z4, Y1, J3 and S2 were the most distant in the direction of the PC2, which indicated that the acidity structure of the slightly acidic sediment was significantly different from that of the other three samples and PC2 was the main factor leading to the differences of the 4 bacterial communities. The main difference between $\mathrm{Z} 4$, $\mathrm{Y} 1$ and $\mathrm{J} 3$ was on the $\mathrm{PC} 1$ axis, $\mathrm{Y} 1$ and $\mathrm{J} 3$ were closer and $\mathrm{Z} 4$ was far from the two, which indicated that the difference of bacterial community between the original and alkaline samples was the smallest; while the difference of $\mathrm{pH}$ between the acid samples and the original samples was only 0.5 , whereas the difference of bacterial community was very different. It can be concluded that the suitable environment for bacteria in the sediment had a critical point of acidity.

As illustrated in Fig. 6, the contribution rate of RDA1 in abscissa was $34.85 \%, \mathrm{PC} 1$ in ordinate was $46.81 \%$ and the total contribution rate was $81.66 \%$ and, S2 was negatively correlated with $\mathrm{PH}$, while $\mathrm{Z} 4, \mathrm{Y} 1$ and $\mathrm{J} 3$ were positively correlated with $\mathrm{pH}$. Interestingly, increasing PH has little impact on species distribution when $\mathrm{r}=0$ (J3) and $\mathrm{r}=0.99(\mathrm{Y} 1)$.

Microbial growth was restricted in the overly acidic environment, while the maximum release of TP was increased in the alkaline environment at $\mathrm{pH}$ of 11.05 and 11.94. With the increase of $\mathrm{pH}$, the release of $\mathrm{TP}$ is mainly ion exchange. In the system, $\mathrm{OH}^{-}$exchanges with the phosphate in the iron and aluminum phosphate complex, which increases the maximum release of phosphorus. A large amount of $\mathrm{OH}^{-}$concentration exists and the anions in the colloid of the sediment compete with each other for adsorption sites, so that TP in the sediment is released. When $\mathrm{pH}$ is 11.94 , the release time of TP to a stable state is shortened due to the influence of $\mathrm{OH}^{-}$concentration. In aqueous solution with high $\mathrm{pH}$, the concentration of $\mathrm{OH}^{-}$ions is large. $\mathrm{NH}_{4}{ }^{+}$released from the sediment colloid reacts with $\mathrm{OH}^{-}$, which is expressed by: $\mathrm{NH}_{4}{ }^{+}+\mathrm{OH}^{-}=\mathrm{NH}_{3}+\mathrm{H}_{2} \mathrm{O}$. As a result, $\mathrm{NH}_{4}{ }^{+}$in TN escapes from the aqueous solution as $\mathrm{NH}_{3}$. The greater the concentration of $\mathrm{OH}^{-}$, the greater theNH4+ escape in the form of $\mathrm{NH} 3$ and the greater the decrease of $\mathrm{TN}$ concentration in aqueous solution.

\section{Composition and Comparison of Community Structure}

The microorganisms involve 23 phyla, 68 classes and 100 genera in the 4 sediment samples and the composition of the microflora at the level of dominant phyla (relative abundance over $1 \%$ ) of each sample is shown in Fig. 7. It can be seen from Fig. 7a that Proteobacteria and Bacteroides are the dominant phylum in four enrichment cultures, among which Proteobacteria has the highest relative abundance, the relative abundance was the highest in S2, more than $57 \%$ and that in $\mathrm{J} 3$ was the lowest, more than $43 \%$; the relative abundance of Bacteroides was S2, Z4, Y1, J3 from high to low in each sample, which was consistent with that of Proteobacteria. In addition, the microbial community 
composition of S2 was significantly different from that of the other three samples in four sediment enrichment samples. For instance, the relative abundance of acidobacteria is the lowest compared with Z4, Y1 and J3, while Proteobacteria and Bacteroidetes have the highest relative abundance. Nitrifying Spirillumnitrospirae, nitrosomonadaceae and nitrosomonadales are the least under acid conditions, as shown in Fig. 7b, which is consistent with the inhibition of nitrification under acid conditions. The abundance of nitrospiare is less than $1 \%$ in the four samples. Denitrifying bacteria are affected by temperature and they are not active enough all the time under the condition of low temperature in winter. Sudarno et al. investigated that the effect of temperature changed on nitrification, the results showed that the ammonia oxidation rate increased from 12.5 to $40^{\circ} \mathrm{C}$, whereas the activity of nitrifying bacteria was very low when the temperature decreased to $6^{\circ} \mathrm{C}$.

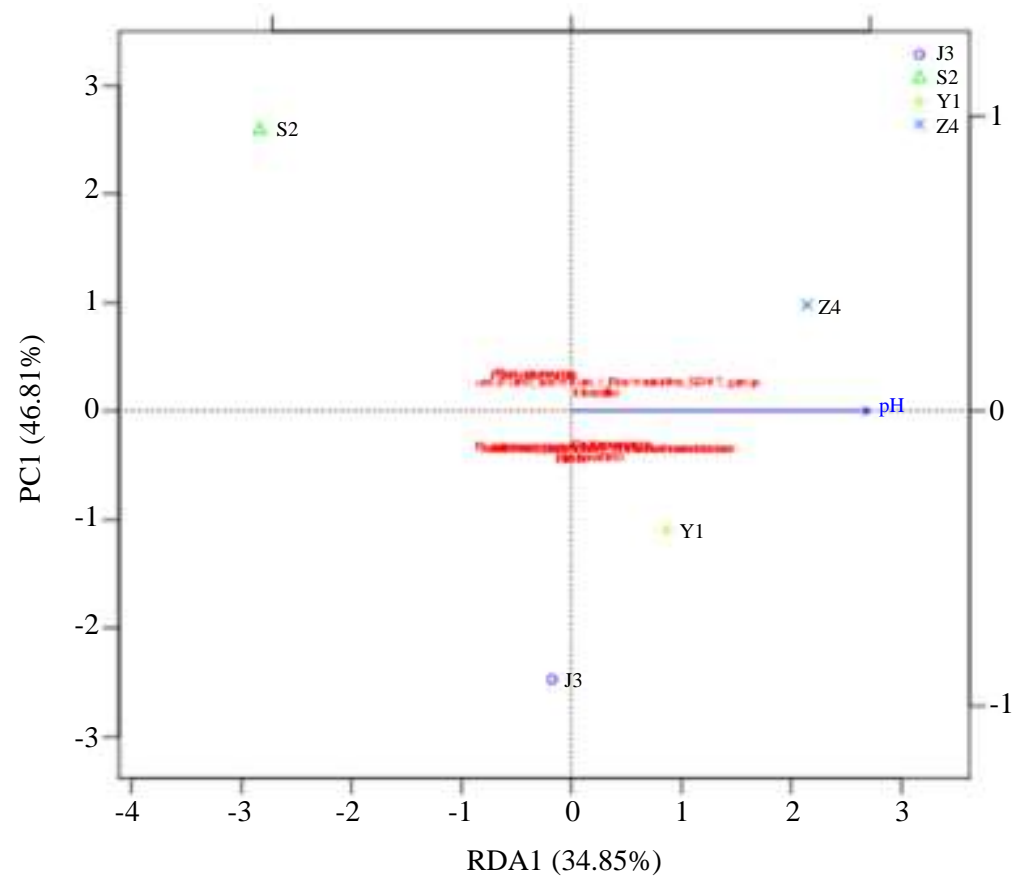

Fig. 6: Analysis of RDA_CCA

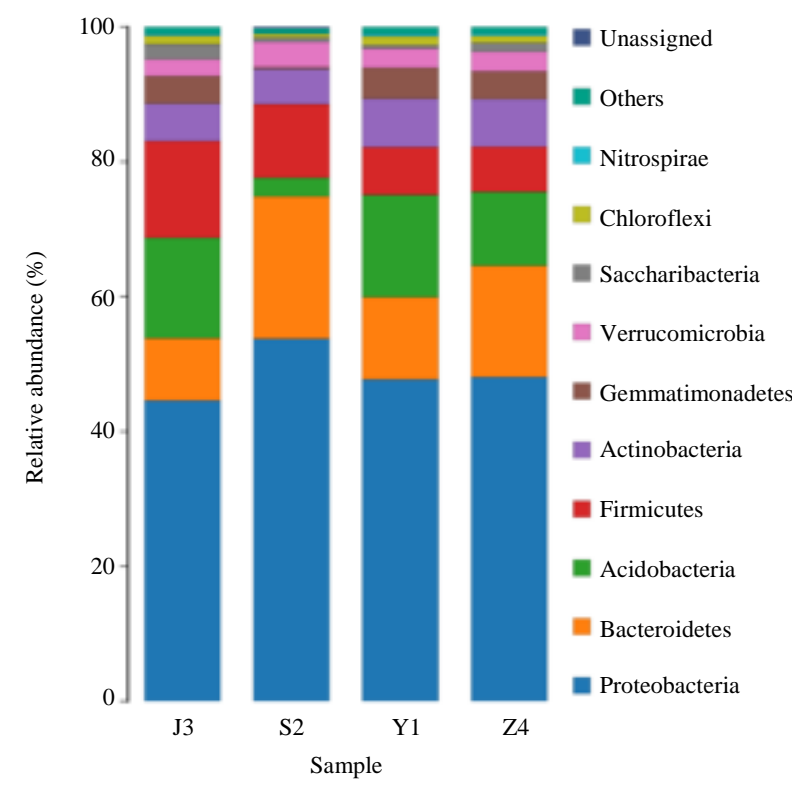

(a)

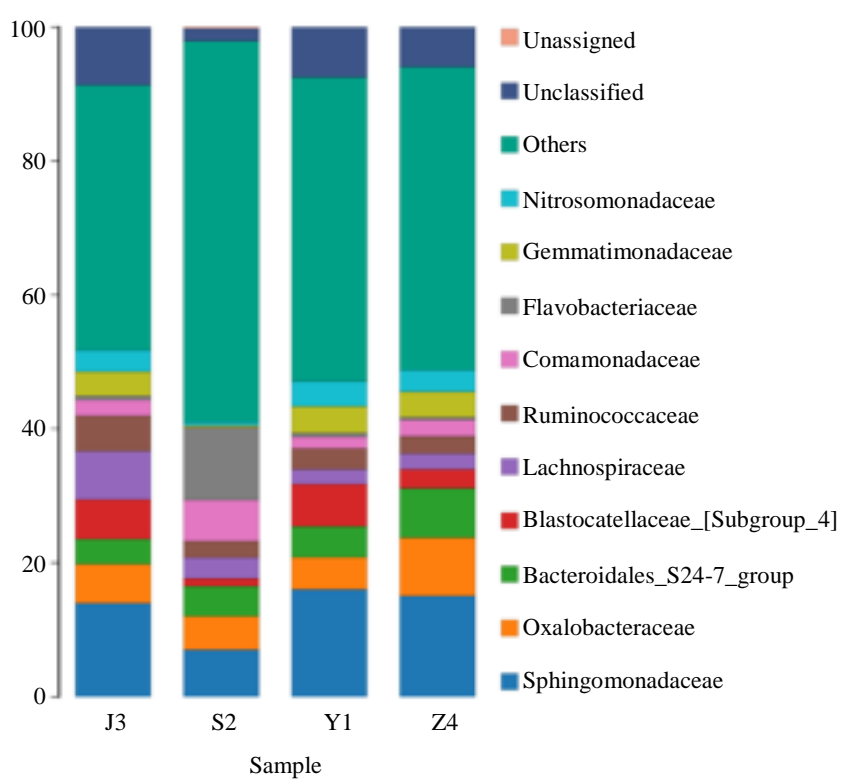

(b) 


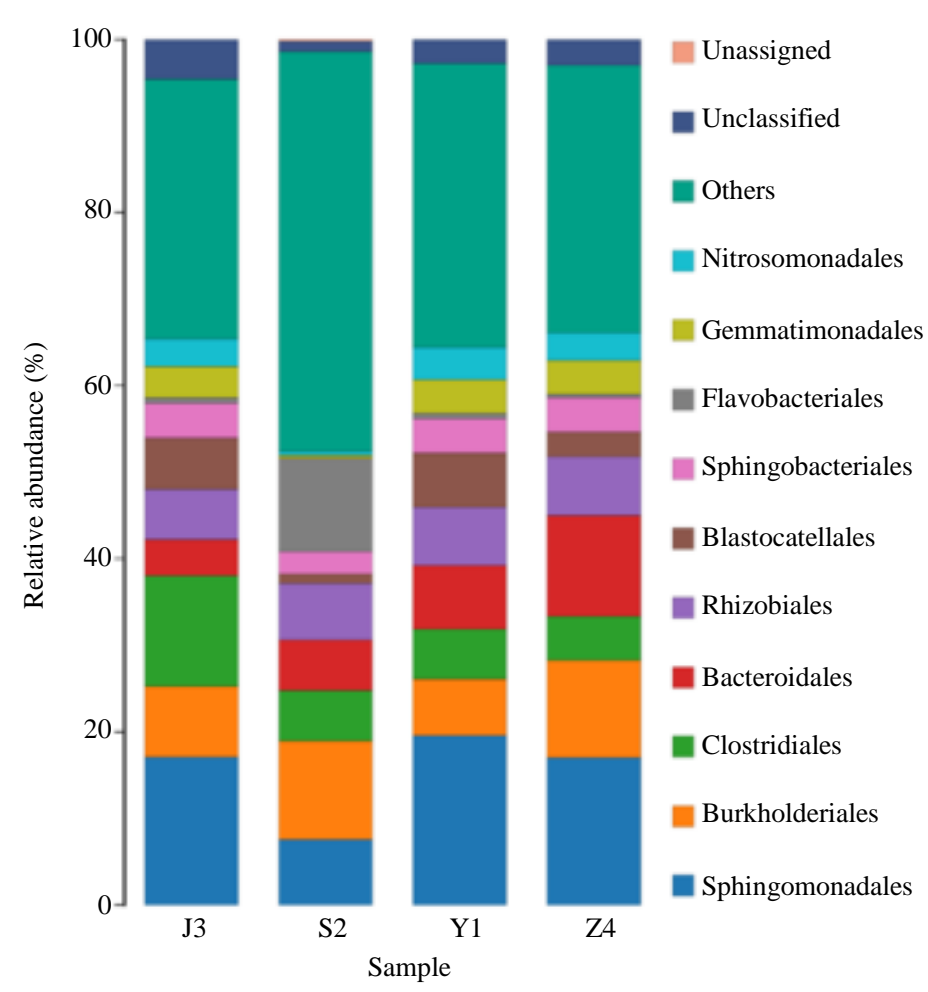

(c)

Fig. 7: Composition of different sediment enrichment samples at phylum

As shown in Fig. 7a, an interesting phenomenon is that Acidobacteria is the least in S2, but have not much different in the other three samples of Z4, Y1 and J3. Naether et al. had found that Acidobacter was more inclined to grow in the sediments of light eutrophic lakes with low organic matter content. As far as we know, little research has been studied on Acidobacteria, whereas it play an important role in ecosystems, such as in sediment. As illustrated in Fig. 7c, the proportion of Flavobacteria in S2 is as high as $15 \%$. It has been found that Flavobacterium of Bacteroides is strongly dependent on organic matter load or phytoplankton bloom and its abundance is very high during cyanobacteria bloom. In winter, the water temperature is low, so the phenomenon of water bloom is not obvious, it is possible that the load of organic matter in the water body is higher.

According to the Venn diagram, the number of shared and unique OTUs among samples can be obtained, as shown in Fig.8, the number of unique OTUs of each sample is different. The number of unique OTUs of Y1, $\mathrm{S} 2, \mathrm{~J} 3$ and Z4 accounts for $0.2,3.5,0.0$ and $0.4 \%$ of the total, respectively. The results revealed that there was no significant difference in community composition among different samples. The OTU Numbers of Y1, S2, J3 and Z4 were 855, 1122 and 1100. The total OTU Numbers of S2, J3 and Z4 were 851 and 847 , respectively and the OTU number of $\mathrm{J} 3$ and $\mathrm{Z} 4$ is 1090 . Among these, the number of OTUs with the same $\mathrm{J} 3$ and Z4 is the highest and the OTUs number with the same S2 and Z4 is the lowest. It can also be seen from the data of common OTU and unique OTU that the community composition of Y1, $\mathrm{S} 2$ and Z4 bacteria is similar to some extent. It should be emphasized that the unique species of $\mathrm{J} 3$ is 0 , which may be the force between sediment minerals and organic matter formed in alkaline condition. Therefore, a large amount of organic matter is adsorbed by minerals in sediment, thus reducing the release to water body.

\section{Analysis of the Functional Bacteria of Ammoxidation}

It can be seen from Fig. 9, the thermo gram of $\mathrm{S} 2$ is contrary to that of the other three samples. Nitrospirae is an important functional group of ammoxidation. The abundance of S2 is the most similar to that of latex bacteria in four samples. The abundance of S2 is less than $5 \%$ in Z4, Y1 and $\mathrm{J} 3$ and less than $1 \%$ in slightly acidic samples. In winter, denitrifying bacteria are not active because of the influence of temperature.

Nitrosomonadaceae, Nitrospirae and Nitrosomonadales were detected in four samples, as listed in Fig. 9. Nitrospira is an important and indispensable group in the nitrogen cycle. It is common in the sediment of freshwater ecosystems. Due to the nitrogen content and $\mathrm{pH}$ of the sediment, the content of nitrospira is different in different eutrophic areas. 


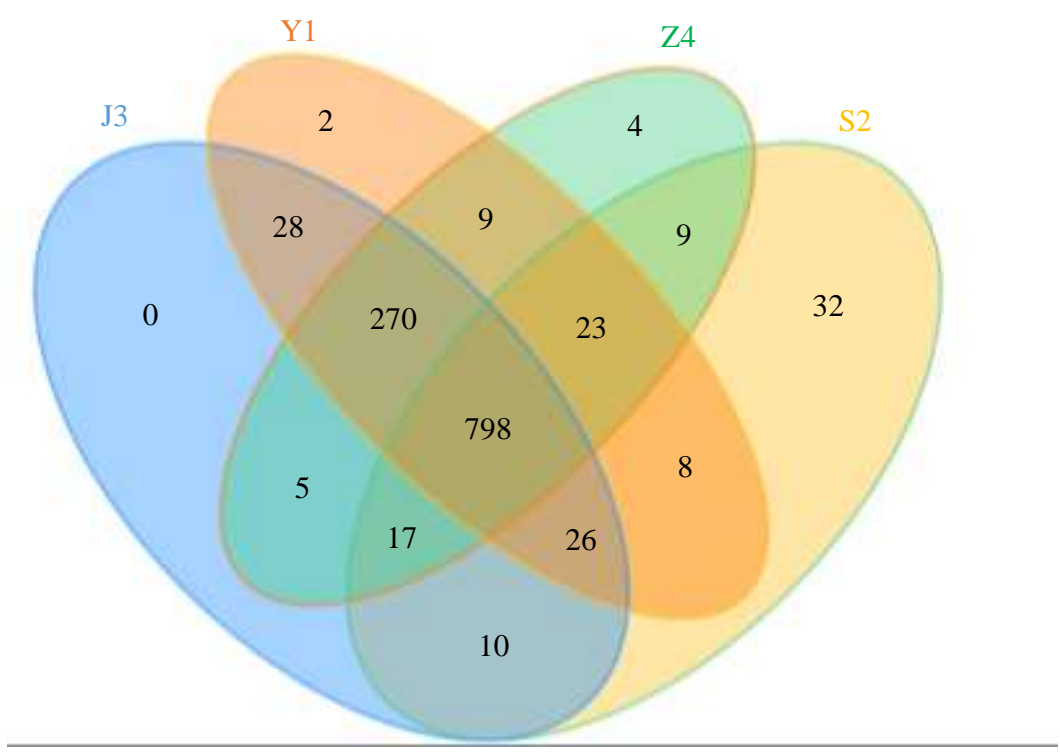

Fig. 8: Venn diagram of OTUs from different sediment enrichment samples

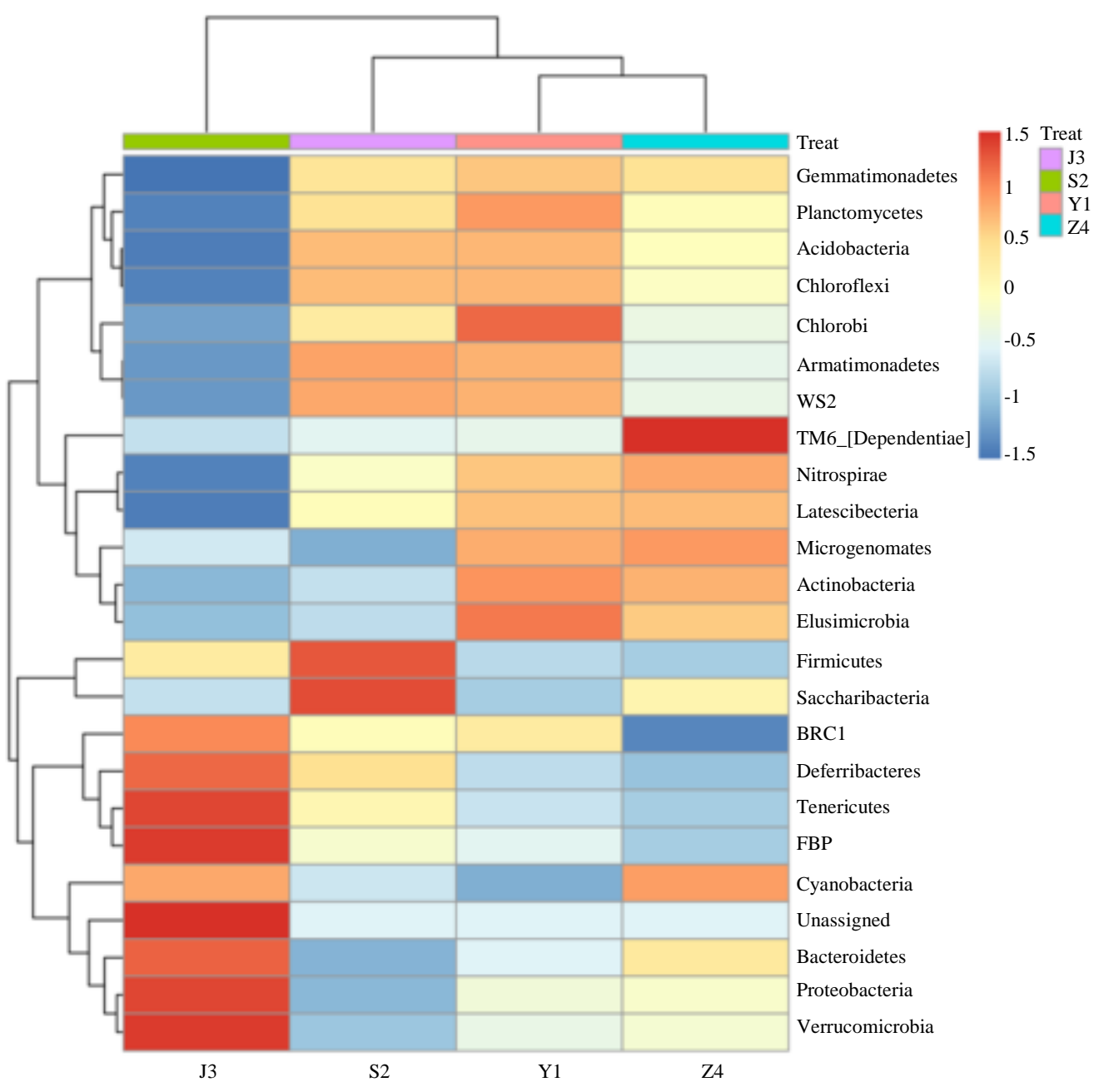

Fig. 9: The thermogram of sample abundance 
The $\mathrm{pH}$ of $\mathrm{Y} 1, \mathrm{~S} 2$ is 5.5 and 5 , respectively. The difference between them is not significant, however, the thermo gram is quite different, which is consistent with that ammonia oxidizing bacteria prefer the slightly alkaline environment. The optimum temperature of ammonia oxidizing bacteria is $24-28^{\circ} \mathrm{C}$ and the temperature of this experiment is about $11^{\circ} \mathrm{C}$, which is far lower than that of ammonia oxidizing bacteria. It can also be confirmed by the fact that the low temperature denitrification effect of sewage plant in winter is not significant and the bacterial activity is not enough.

\section{Conclusion}

In this study, the sediment of Pi River was taken as research objectives and prepared to sample with varying the $\mathrm{pH}$, which is tested by the high-throughput sequencing technology. On the basis of the above experiment, several key conclusions were draw as follows: (1) The bacterial community of different $\mathrm{pH}$ was studied where the place was the bottom mud of the Pi River. An analysis was done not only at the level of classification, but also at the level of genus classification. It was found that many unclassified bacteria and uncultured bacteria were exited, which indicated that there were a lot of potential new species in the bottom mud ecosystem of the $\mathrm{Pi}$ River. In addition, more than $40 \%$ of the bacteria in the sediment samples had an average relative abundance less than $1.5 \%$ at the genus level, which indicated the bacterial community was relatively scattered and have high diversity in the Pi River sediment; (2) the $\mathrm{pH}$ of the acid sample was 5 and that of the original sediment sample was 5.5, which have not significant difference of $\mathrm{pH}$ between the two samples, whereas the richness and evenness of S2 samples were significantly reduced. Compared with Z4, Y1 and J3, Acidobacteria of acid samples had the lowest relative abundance, while Proteobacteria and Bacteroidetes have the highest relative abundance, which indicated that acidic environment has relatively obvious influence on microorganisms, while alkaline environment has little influence on original microorganisms. It may be closely related to the physiological activities of microorganisms and the $\mathrm{pH}$ of the environment. The normal physiological activities of microorganisms can be carried out under the appropriate $\mathrm{pH}$ conditions;(3) three ammoxidation functional group were detected in four samples in winter, which included Nitrosomonadaceae, Nitrospirae and Nitrosomonadales, the abundance of Z4, Y1 and J3 was less than 5\%, whereas less than $1 \%$ in the slightly acidic samples. It was clear that the acidic environment had a greater impact on the Nitrilothia.

Additionally, this study only selected the $\mathrm{pH}$ as a single factor to analyze, which failed to take the cross effect of multiple factors into account. In the future, the research should be considered with the influence of multiple factors and microbial community structure, namely, the sediment of Pi River from the perspective of dynamic variation will be investigated.

\section{Acknowledgement}

This research was funded by the Anhui Natural Science Foundation Youth Project (JZ2019AKZR0248); the key project of Anhui university natural science (KJ2017A411), the Key project of West Anhui university natural science (WXZR202023).

\section{Author's Contributions}

Cairui Yu and Dongmei Shen: Designed and performed the experiments, work.

Yulan Gao and Wanfen Wang: Participated to collect the materials related to the experiment.

Xinwei Song, Youxiao Tu and Xing Jin: Designed the experiments and revised the manuscript.

\section{Ethics}

The authors declare their responsibility for any ethical issues that may arise after the publication of this manuscript.

\section{Conflict of Interest}

The authors declare that they have no competing interests. The corresponding author affirms that all of the authors have read and approved the manuscript.

\section{References}

Bai, Y., Qi, W., Liang, J., \& Qu, J. (2014). Using highthroughput sequencing to assess the impacts of treated and untreated wastewater discharge on prokaryotic communities in an urban river. Applied Microbiology and Biotechnology 98(4), 1841-1851. https://doi.org/10.1007/s00253-0135116-2

Biggs, B. J. F. (2000). Eutrophication of streams and rivers: dissolved nutrient-chlorophyll relationships for benthic algae. Journal of the North American Benthological Society 19(1), 17-31. https://doi.org/10.2307/1468279

Billard, E., Domaizon, I., Tissot, N., Arnaud, F., \& Lyautey, E. (2015). Multi-scale phylogenetic heterogeneity of archaea, bacteria, methanogens and methanotrophs in lake sediments. Hydrobiologia, 751(1), 159-173. https://doi.org/10.1007/s10750015-2184-6 
Chen, N., Yang, J. S., Qu, J. H., Li, H. F., Liu, W. J., Li, B. Z., ... \& Yuan, H. L. (2015). Sediment prokaryote communities in different sites of eutrophic Lake Taihu and their interactions with environmental factors. World Journal of Microbiology and Biotechnology, 31(6), 883-896. https://doi.org/10.1007/s11274-015-1842-1

Ćosić-Flajsig, G., Vučković, I., \& Karleuša, B. (2020). An Innovative Holistic Approach to an E-flow Assessment Model. Civil Engineering Journal, 6(11), 2188-2202. https://doi.org/10.28991/cej2020-03091611

Crump, B. C., Adams, H. E., Hobbie, J. E., \& Kling, G. W. (2007). Biogeography of bacterioplankton in lakes and streams of an arctic tundra catchment. Ecology, 88(6), 1365-1378. https://doi.org/10.1890/06-0387

Flynn, K. F., Chapra, S. C., \& Suplee, M. W. (2013). Modeling the lateral variation of bottom-attached algae in rivers. Ecological Modelling, 267, 11-25. https://doi.org/10.1016/j.ecolmodel.2013.07.011

García-Armisen, T., İnceoğlu, Ö., Ouattara, N. K., Anzil, A., Verbanck, M. A., Brion, N., \& Servais, P. (2014). Seasonal variations and resilience of bacterial communities in a sewage polluted urban river. PloS One, 9(3), e92579. https://doi.org/10.1371/journal.pone.0092579

Howarth, R. W., Anderson, D., Cloern, J. E., Elfring, C., Hopkinson, C. S., Lapointe, B., ... \& Sharpley, A. N. (2000). Issues in Ecology: Nutrient Pollution of Coastal Rivers. Bays and Seas, 1-16.

Jalili, M., Ghasemi, M. R., \& Pifloush, A. R. (2018). Stiffness and strength of granular soils improved by biological treatment bacteria microbial cements. Emerging Science Journal, 2(4), 219-227. https://doi.org/10.28991/esj-2018-01146

Jiménez-Rodríguez, A., Serrano, A., Benjumea, T., Borja, R., Kaoutit, M., \& Fermoso, F. G. (2019). Decreasing microbial fuel cell start-up time using multi-walled carbon nanotubes. Emerging Science Journal, 3(2), 109. https://doi.org/10.28991/esj2019-01174

Kaestli, M., Skillington, A., Kennedy, K., Majid, M., Williams, D., McGuinness, K., \& Gibb, K. (2017) Spatial and temporal microbial patterns in a tropical macrotidal estuary subject to urbanization. Frontiers in Microbiology, $8, \quad 1313$. https://doi.org/10.3389/fmicb.2017.01313

Kirchman, D. L. (1994). The uptake of inorganic nutrients by heterotrophic bacteria. Microbial Ecology, 28(2), 255-271. https://doi.org/10.1007/BF00166816
Lapanje, A., Drobne, D., Nikcevic, S., Perović, A., Zidar, P., Štrus, J., \& Karaman, G. (2005). Bacterial Community Structure Analyses to Assess Pollution of Water and Sediments in the Lake Shkodra/Skadar, Balkan Peninsula (8 pp). Environmental Science and Pollution Research, 12(6), 361-368. https://doi.org/10.1065/espr2005.07.271

Lindström, E. S., Kamst-Van Agterveld, M. P., \& Zwart, G. (2005). Distribution of typical freshwater bacterial groups is associated with $\mathrm{pH}$, temperature and lake water retention time. Applied and Environmental Microbiology, 71(12), 8201-8206. https://doi.org/10.1128/AEM.71.12.8201-8206.2005

Lundgaard, A. S. B., Treusch, A. H., Stief, P., Thamdrup, B., \& Glud, R. N. (2017). Nitrogen cycling and bacterial community structure of sinking and aging diatom aggregates. Aquatic Microbial Ecology, 79(2), 85-99. https://doi.org/10.3354/ame01821

Mark Ibekwe, A., Leddy, M. B., Bold, R. M., \& Graves, A. K. (2012). Bacterial community composition in low-flowing river water with different sources of pollutants. FEMS Microbiology Ecology, 79(1), 155-166. https://doi.org/10.1111/j.15746941.2011.01205.x

Metwally, G. A., Mahdy, M., \& Abd El, A. E. R. H. (2020). Performance of Bio Concrete by Using Bacillus Pasteurii Bacteria. Civil Engineering Journal, 6(8), 1443-1456. https://doi.org/10.28991/cej-2020-03091559

Ruiz-González, C., Niño-García, J. P., \& Del Giorgio, P. A. (2015). Terrestrial origin of bacterial communities in complex boreal freshwater networks. Ecology Letters, 18(11), 1198-1206. https://doi.org/10.1111/ele.12499

Scharnberg, A. A., de Loreto, A. C., \& Alves, A. K. (2020). Optical and structural characterization of Bi2FexNbO7 nanoparticles for environmental applications. Emerging Science Journal, 4(1), 11-17. https://doi.org/10.28991/esj-2020-01205

Tiquia, S. M. (2010). Metabolic diversity of the heterotrophic microorganisms and potential link to pollution of the Rouge River. Environmental Pollution, 158(5), 1435-1443. https://doi.org/10.1016/j.envpol.2009.12.035

Torres-Alvarado, M. D. R., Calva-Benítez, L. G., Álvarez-Hernández, S., \& Trejo-Aguilar, G. (2016). Anaerobic microbiota: spatial-temporal changes in the sediment of a tropical coastal lagoon with ephemeral inlet in the Gulf of Mexico. Revista de Biologia Tropical, 64(4), 1759-1770. https://doi.org/10.15517/rbt.v64i4.22449 
Wang, L., Zhang, J., Li, H., Yang, H., Peng, C., Peng, Z., \& Lu, L. (2018). Shift in the microbial community composition of surface water and sediment along an urban river. Science of the Total Environment, 627,

600-612. https://doi.org/10.1016/j.scitotenv.2018.01.203

Wang, P., Rene, E. R., Yan, Y., Ma, W., \& Xiang, Y. (2019). Spatiotemporal evolvement and factors influencing natural and synthetic EDCs and the microbial community at different groundwater depths in the Chaobai watershed: A long-term field study on a river receiving reclaimed water. Journal of Environmental Management, 246, 647-657. https://doi.org/10.1016/j.jenvman.2019.05.156

Xie, Y., Wang, J., Wu, Y., Ren, C., Song, C., Yang, J., \& Zhang, X. (2016). Using in situ bacterial communities to monitor contaminants in river sediments. Environmental Pollution, 212, 348-357. https://doi.org/10.1016/j.envpol.2016.01.031
Zhang, M., Wu, Z., Sun, Q., Ding, Y., Ding, Z., \& Sun, L. (2019). Response of chemical properties, microbial community structure and functional genes abundance to seasonal variations and human disturbance in Nanfei River sediments. Ecotoxicology and Environmental Safety, 183, 109601. https://doi.org/10.1016/j.ecoenv.2019.109601

Zhou, C., Zhou, Q., \& Zhang, X. (2019). Transformation of acetaminophen in natural surface water and the change of aquatic microbes. Water Research, 148, 133-141. https://doi.org/10.1016/j.watres.2018.10.042 